\title{
Reduced food access due to a lack of money, inability to lift and lack of access to a car for food shopping: a multilevel study in Melbourne, Victoria
}

\author{
Cate Burns $^{1, *}$, Rebecca Bentley ${ }^{2}$, Lukar Thornton ${ }^{3}$ and Anne Kavanagh ${ }^{2}$ \\ 'WHO Collaborating Centre for Obesity Prevention, Deakin University, Burwood, VIC 3125 , Australia: \\ ${ }^{2}$ Centre for Women's Health, Gender \& Society, Melbourne School of Population Health, University of \\ Melbourne, Melbourne, Australia: ${ }^{3}$ Centre for Physical Activity and Nutrition Research, Deakin University, \\ Melbourne, Australia
}

Submitted 3 May 2010: Accepted 14 December 2010: First published online 22 February 2011

\begin{abstract}
Objective: To describe associations between demographic and individual and arealevel socio-economic variables and restricted household food access due to lack of money, inability to lift groceries and lack of access to a car to do food shopping. Design: Multilevel study of three measures of restricted food access, i.e. running out of money to buy food, inability to lift groceries and lack of access to a car for food shopping. Multilevel logistic regression was conducted to examine the risk of each of these outcomes according to demographic and socio-economic variables.

Setting: Random selection of households from fifty small areas in Melbourne, Australia, in 2003.

Subjects: The main food shoppers in each household ( $n$ 2564)

Results: A lack of money was significantly more likely among the young and in households with single adults. Difficultly lifting was more likely among the elderly and those born overseas. The youngest and highest age groups both reported reduced car access, as did those born overseas and single-adult households. All three factors were most likely among those with a lower individual or household socio-economic position. Increased levels of area disadvantage were independently associated with difficultly lifting and reduced car access.

Conclusions: In Melbourne, households with lower individual socio-economic position and area disadvantage have restricted access to food because of a lack of money and/or having physical limitations due difficulty lifting or lack of access to a car for food shopping. Further research is required to explore the relationship between physical restrictions and food access.
\end{abstract}

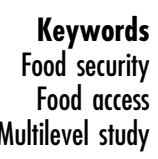

Keywords Food security Multilevel study
As in many countries, a significant number of Australians do not eat a healthy diet ${ }^{(1)}$. Poor diet accounts for $9 \%$ of the burden of disease in Australia and the estimated annual economic cost of diet-related diseases such as obesity is \$AU 60 billion $^{(2)}$.

The consumption of a healthy diet is determined by food security, which entails people having, at a minimum, the ready availability of nutritionally adequate and safe foods and an assured ability to acquire foods in socially acceptable ways ${ }^{(3)}$. Conversely, food insecurity 'refers to the social and economic problems of lack of food due to resource or other constraints, not voluntary fasting or dieting, or because of illness or other reasons, ${ }^{(4)}$. Epidemiological studies indicate that food insecurity is strongly related to poor nutritional intakes ${ }^{(5)}$, poor self-reported health $^{(6)}$ and chronic disease $e^{(7,8)}$. Food security is itself dependent on access to adequate amounts of nutritious food $^{(9)}$. Lack of economic resources is the most common constraint to food access ${ }^{(4)}$. However, other constraints such as a lack of physical functioning or disability or lack of transport may lead to food insecurity via a decreased capacity to acquire food even though food may be available and accessible ${ }^{(10)}$.

Poor access to enough nutritious food is a major and highly visible issue in low-income countries but relative deprivation exists in high-income countries such as USA, Canada, the UK, New Zealand and Australia, where limited access to food as a consequence of economic resources is well described ${ }^{(11-14)}$. However, while there are studies in both representative samples and high-risk populations of food access limited by economic resources ${ }^{(15-19)}$, there has been limited research examining physical constraints to food access, although these additional factors have been hypothesised to restrict to access 
and impact on food intake particularly in the elderly ${ }^{(10)}$. Previous research, reviewed by White ${ }^{(20)}$, highlighted the role of car access in the choice of food outlets. The role of car access and disability has been indicated in both qualitative $^{(21-23)}$ and quantitative studies of hunger and food insecurity in the elderly ${ }^{(24,25)}$. Physical limitations to food access are likely to be prevalent problems. For example in Australia, 13\% the population is over the age of 65 years and $20 \%$ of the population has a disability, with $86 \%$ of the disabled being limited in core activities of selfcare, mobility or communication ${ }^{(19,26)}$. Also in Australia, in 2007 passenger vehicles accounted for $73 \%$ of all trips by motor vehicles, with $51 \%$ of these distances accounted for by personal use as opposed to travel to work or for business ${ }^{(27)}$. This number is likely to have increased with an increase in car ownership and a fall in the use of public transport ${ }^{(28)}$. Although car ownership figures are high, a significant number $(8 \%)$ of people live in dwellings with no registered cars ${ }^{(28)}$. The lack of a car or dependence on public transport may restrict the access to food for these householders. It is important to examine more thoroughly the extent of and risk factors for not only economic but also physical restrictions to buying food.

Using data from the 2564 participants in the Victorian Lifestyle and Neighbourhood Environments Study (VicLANES) conducted in Melbourne, Australia, in the present paper we examine the associations between demographic and socioeconomic variables and restricted household food access due to (i) lack of money, (ii) inability to lift groceries and (iii) lack of access to a car for food shopping.

\section{Experimental methods}

\section{Study design}

We analysed data collected in 2003 as part of VicLANES, a cross-sectional multilevel study conducted within a single metropolitan context: Melbourne, Australia. Prior to sampling, all Census Collector Districts (CCD; average size of about 220 dwellings in urban areas ${ }^{(29)}$ ) across metropolitan Melbourne were stratified into septiles based on the proportion of households in each CCD with a total household weekly income of less than \$AU 400. Fifty CCD were then randomly selected from the least (mean proportion of low-income households $7 \cdot 0 \%$, range $3.5-8.5 \% ; n$ 17), mid (mean $15 \cdot 3 \%$, range $14 \cdot 4-16 \cdot 7 \%$; $n$ 16) and most disadvantaged (mean $31.4 \%$, range $24 \cdot 1-59 \cdot 6 \% ; n$ 17) septiles. Sampling in this way maximised the area-level socio-economic exposure gradient. Households were randomly sampled from these fifty CCD. A Food Purchasing survey was mailed to 3995 selected households and was to be completed by the person who undertook the majority of food shopping. A total of 2564 valid responses were received (64\% response rate). The VicLANES project was approved by the La Trobe University Human Ethics Committee.

\section{Dependent variable}

Our three measures of restricted food access were determined by asking the following questions:

1. In the last 12 months, were there any times when you ran out of food and could not afford to buy more?

2. Does your health limit the lifting or carrying of groceries?

3. Do you always have access to a car to do your food shopping?

Each question had a binary (yes/no) response category. Restricted food access was indicated by the answer 'yes' to questions and 2 and 'no' to question 3.

\section{Predictor variables and confounders}

Variables related to age, country of birth, education and occupation were based on the main food shopper, whereas household composition and income were collected at a household level. Age was coded into six categories (18-24, $25-34,35-44,45-54,55-64$ or $\geq 65$ years). Country of birth was a binary variable defined by whether the respondent was born in Australia or overseas. Four categories of education (bachelor degree or higher; diploma (associate or undergraduate); vocational; no post-school qualification) were created. Respondent occupation was coded to the Australian Bureau of Statistics' Australian Standard Classification of Occupations ${ }^{(30)}$, with the final categories being professional employees (managers; administrators; professionals; para-professionals), white-collar employees (clerks; salespersons; personal service workers), blue-collar employees (tradespersons; machine operators; drivers; labourers; related workers) or not in the labour force (retired; studying; unemployed; not looking for work; unable to work). Five categories of household composition were used (single male adult without children; single female adult without children; single adult with a child or children; two or more adults without children; two or more adults with a child or children). Total household income was coded into five categories (\$AU 20799 or less; \$AU 20 800-36 399; \$AU 36 400-51 999; \$AU 52 000-77 999; \$AU 78000 or more). Household-level income variables have previously been reported as the best measures for determining relationships with purchasing ${ }^{(31)}$. As described above under 'Study design' there were three categories of area-level disadvantage: least, mid and most disadvantaged. For analysis baseline categories were set for groups that contained the highest number of respondents or were the highest category for socio-economic predictors so that trends could more easily be seen.

\section{Missing data imputation}

Rather than analysing the complete cases only and thus potentially biasing estimates, missing data were imputed under the MAR (missing at random) assumption. Under this assumption the missing values were modelled as a function of observed variables. Ten data sets with 
imputed values for missing items on each variable were estimated using the user-written ICE (Imputation by Chained Equations) command (P Royston) in the STATA statistical software package version 10.0 (StataCorp LP, College Station, TX, USA). This program uses switching regression, an iterative multivariable regression technique, to estimate missing values. Analysing multiple imputed data provides more rigorous estimates of possible effect sizes than other approaches to missing data, as standard errors are adjusted for variation in imputed values across each of the data sets ${ }^{(32)}$.

\section{Descriptive analysis}

The proportions of households experiencing the three measures of restricted food access were determined by age group, country of birth, household composition, education, occupation, household income and area-level disadvantage. Ninety-five per cent confidence intervals were calculated around these proportions.

\section{Multilevel analysis}

Multilevel logistic regression was undertaken in STATA version $10 \cdot 1$ prefixed by the user-written 'mim' command (created by JC Galati, P Royston and JB Carlin) which allowed for analysis to be undertaken across multiple data sets. Results from the multilevel analysis were presented as odds ratios with $95 \%$ confidence intervals.

The aim of the analyses was to test to associations between our three measures of restricted food access and demographic and socio-economic predictors. We assessed whether there was a significant trend in the association between socio-economic characteristics and restricted food access by fitting education, occupation, income and area disadvantage as continuous variables. Analyses were run separately for each outcome. To assess the independent effects of each of the predictors we adjusted models for potential confounders. Covariates included in the models were those hypothesised to be potential prior causes of both the predictor variable and restricted access to food. Analyses of the association between age and country of birth and restricted food access did not include any covariates. Household composition, education, occupation, income and area disadvantage were all adjusted for age and country of birth. Based on the conceptualisation of education being a determinant of occupation which in turn influences income, we further adjusted occupation for education and income for both education and occupation. Area disadvantage was adjusted for all demographic and socio-economic covariates.

\section{Results}

\section{Descriptive analysis}

Table 1 shows that the estimate of the prevalence of restricted access to food due to having no money was
$8 \cdot 1 \%$, due to difficulty lifting was $19 \cdot 1 \%$, and due to having no car access was $15 \cdot 0 \%$. Restricted food access on each of the three measures was more likely in those on the lowest income and living in the most disadvantaged neighbourhoods. Variations were also observed due to age, being born overseas, household composition, education and labour force status (Table 1).

\section{Multilevel analysis}

\section{Lack of money}

Multilevel analyses (Table 2) indicate that lack of money for food was inversely associated with age ( $P$ for trend $<0 \cdot 001)$. In comparison with households made up of two adults with children, single adult males and females were over three times more likely to have no money for food while single-parent households with children had fourfold greater risk $(\mathrm{OR}=4 \cdot 23 ; 95 \% \mathrm{CI} 2 \cdot 67,6 \cdot 72)$. Compared with those who had a bachelor degree or higher, respondents in each of the lower education categories were more than twice as likely to report they ran out of money to buy food. Those who were not in the labour force were three times more likely compared with professionals to run out of money for food (OR $=3 \cdot 00 ; 95 \%$ CI $1 \cdot 87,4 \cdot 81)$. We found a strong association between having no money for food and income, with the likelihood increasing with decreasing income $(P$ for trend $<0 \cdot 001$ ). Those in the lowest income group were over twelve times more likely run out of money to buy food (OR $=12 \cdot 68$; 95\% CI 5.15, $31 \cdot 2)$. No significant association was found for country of birth or area-level disadvantage once other covariates were included in the models.

\section{Difficulty carrying groceries}

A strong linear association was found for age and difficulty lifting groceries, with the elderly most likely to report this was the case ( $P$ for trend $<0 \cdot 001$; Table 2 ). Those born overseas were significantly more likely to have difficulty lifting groceries compared with those born in Australia (OR $=1 \cdot 60 ; 95 \%$ CI 1.29, 1.99). Adjusted analyses showed those with lower education qualifications (vocation or no post-school qualifications) were more likely to report difficulty lifting compared with those having a bachelor degree, as were those not in the labour force compared with those in professional employment. The likelihood of having difficulty carrying groceries increased as income decreased, with those in the lowest bracket of income nearly six times more likely to have food access restricted by difficulty lifting ( $\mathrm{OR}=$ 5.60; 95\% CI 3.49, 9.00). There was also a significant effect for area-level disadvantage; those living in the most disadvantaged areas had $65 \%$ increased odds of having difficulty lifting groceries (OR $=1 \cdot 65 ; 95 \%$ CI $1 \cdot 20,2 \cdot 28)$.

\section{Limited car access}

The youngest $(\mathrm{OR}=2 \cdot 66 ; 95 \% \mathrm{CI} 1 \cdot 36,5 \cdot 21)$ and oldest age groups $(\mathrm{OR}=2 \cdot 48 ; 95 \%$ CI $1.73,3 \cdot 55)$ were most 
Table 1 Crude prevalence of food insecurity due lack of money, poor health and poor access to a car in relation to demographic variables, household composition, education, occupation, income and area-level advantage/disadvantage: the Victorian Lifestyle and Neighbourhood Environments Study, Melbourne, Australia, 2003

\begin{tabular}{|c|c|c|c|c|c|c|c|c|c|c|c|}
\hline & \multicolumn{2}{|c|}{ Total } & \multicolumn{3}{|c|}{ No money for foodt } & \multicolumn{3}{|c|}{ Difficulty lifting } & \multicolumn{3}{|c|}{ Do not have car access§ } \\
\hline & $n$ & $\%$ & $n$ & $\%$ & $P$ value & $n$ & $\%$ & $P$ value & $n$ & $\%$ & $P$ value \\
\hline Total & 2564 & & 206 & $8 \cdot 1$ & & 487 & $19 \cdot 1$ & & 382 & $15 \cdot 0$ & \\
\hline \multicolumn{12}{|l|}{ Age (years) } \\
\hline $18-24$ & 56 & $2 \cdot 2$ & 9 & $16 \cdot 0$ & & 2 & $3 \cdot 6$ & & 16 & $28 \cdot 5$ & \\
\hline 25-34 & 365 & $14 \cdot 2$ & 36 & $9 \cdot 9$ & & 28 & $7 \cdot 7$ & & 50 & $13 \cdot 8$ & \\
\hline $35-44$ & 568 & $22 \cdot 2$ & 50 & $8 \cdot 9$ & & 63 & $11 \cdot 4$ & & 65 & $11 \cdot 7$ & \\
\hline $45-54$ & 680 & $26 \cdot 5$ & 64 & $9 \cdot 6$ & & 120 & $18 \cdot 1$ & & 75 & $11 \cdot 2$ & \\
\hline $55-64$ & 501 & $19 \cdot 5$ & 27 & $5 \cdot 5$ & & 125 & $25 \cdot 1$ & & 73 & $14 \cdot 7$ & \\
\hline$\geq 65$ & 394 & $15 \cdot 4$ & 19 & $5 \cdot 1$ & 0.003 & 145 & $37 \cdot 2$ & $<0.001$ & 100 & $26 \cdot 1$ & $<0.001$ \\
\hline \multicolumn{12}{|l|}{ Country of birth } \\
\hline Australia & 1773 & $69 \cdot 2$ & 152 & $8 \cdot 7$ & & 290 & $16 \cdot 5$ & & 229 & $13 \cdot 0$ & \\
\hline Overseas & 791 & $30 \cdot 8$ & 54 & $6 \cdot 9$ & $0 \cdot 112$ & 196 & $25 \cdot 1$ & $<0.001$ & 152 & $19 \cdot 6$ & $<0.001$ \\
\hline \multicolumn{12}{|l|}{ Household composition } \\
\hline Single adult male, no children & 169 & $6 \cdot 6$ & 27 & $16 \cdot 7$ & & 27 & $17 \cdot 1$ & & 49 & $30 \cdot 5$ & \\
\hline Single adult female, no children & 272 & $10 \cdot 6$ & 33 & $12 \cdot 7$ & & 75 & $28 \cdot 2$ & & 82 & $30 \cdot 8$ & \\
\hline Single, with children & 194 & $7 \cdot 6$ & 39 & $20 \cdot 1$ & & 44 & $23 \cdot 3$ & & 31 & $16 \cdot 3$ & \\
\hline Two or more adults, no children & 902 & $35 \cdot 2$ & 45 & $5 \cdot 2$ & & 173 & $19 \cdot 5$ & & 113 & $13 \cdot 0$ & \\
\hline Two or more adults, with children & 1027 & $40 \cdot 0$ & 57 & $5 \cdot 8$ & $<0.001$ & 162 & $15 \cdot 9$ & $<0.001$ & 96 & $9 \cdot 9$ & $<0.001$ \\
\hline \multicolumn{12}{|c|}{ Education } \\
\hline Bachelor degree or higher & 790 & $30 \cdot 8$ & 34 & $4 \cdot 5$ & & 92 & $12 \cdot 0$ & & 72 & $9 \cdot 4$ & \\
\hline Diploma & 284 & $11 \cdot 1$ & 24 & $8 \cdot 8$ & & 39 & $14 \cdot 6$ & & 32 & $11 \cdot 6$ & \\
\hline Vocational & 396 & $15 \cdot 4$ & 40 & $10 \cdot 8$ & & 73 & $19 \cdot 1$ & & 51 & $13 \cdot 7$ & \\
\hline No post-school qualifications & 1094 & $42 \cdot 7$ & 102 & $9 \cdot 6$ & $<0.001$ & 275 & $25 \cdot 4$ & $<0.001$ & 219 & $20 \cdot 4$ & $<0.001$ \\
\hline \multicolumn{12}{|l|}{ Occupation } \\
\hline Professional & 834 & $32 \cdot 5$ & 39 & $4 \cdot 8$ & & 86 & $10 \cdot 4$ & & 58 & $7 \cdot 1$ & \\
\hline White-collar employees & 504 & $19 \cdot 7$ & 43 & $8 \cdot 8$ & & 54 & $11 \cdot 2$ & & 57 & $11 \cdot 8$ & \\
\hline Blue-collar employees & 146 & $5 \cdot 7$ & 14 & $10 \cdot 0$ & & 14 & $10 \cdot 5$ & & 21 & $15 \cdot 2$ & \\
\hline Not in labour force & 1080 & $42 \cdot 1$ & 107 & $10 \cdot 2$ & $<0.001$ & 328 & $30 \cdot 8$ & $<0.001$ & 240 & $22 \cdot 7$ & $<0.001$ \\
\hline \multicolumn{12}{|l|}{ Income } \\
\hline$\$ A U 78000$ or more & 714 & $27 \cdot 9$ & 9 & $2 \cdot 0$ & & 62 & $9 \cdot 5$ & & 35 & $6 \cdot 0$ & \\
\hline \$AU $52000-77999$ & 520 & $20 \cdot 3$ & 15 & $3 \cdot 6$ & & 53 & $11 \cdot 0$ & & 41 & $8 \cdot 7$ & \\
\hline \$AU $36400-51999$ & 387 & $15 \cdot 1$ & 30 & $8 \cdot 8$ & & 50 & $13 \cdot 7$ & & 37 & $11 \cdot 3$ & \\
\hline \$AU 20800-36399 & 433 & $16 \cdot 9$ & 44 & $10 \cdot 8$ & & 87 & $21 \cdot 6$ & & 70 & $17 \cdot 8$ & \\
\hline \$AU 20799 or less & 510 & $19 \cdot 9$ & 90 & $18 \cdot 3$ & $<0.001$ & 208 & $42 \cdot 5$ & $<0.001$ & 166 & $34 \cdot 3$ & $<0.001$ \\
\hline \multicolumn{12}{|l|}{ Area-level disadvantage } \\
\hline Least disadvantaged & 914 & $35 \cdot 7$ & 34 & $3 \cdot 8$ & & 116 & $12 \cdot 8$ & & 56 & $6 \cdot 2$ & \\
\hline Mid disadvantaged & 895 & $34 \cdot 9$ & 82 & $9 \cdot 2$ & & 170 & $19 \cdot 3$ & & 146 & $16 \cdot 5$ & \\
\hline Most disadvantaged & 755 & $29 \cdot 5$ & 90 & $12 \cdot 1$ & $<0.001$ & 198 & $26 \cdot 5$ & $<0.001$ & 178 & $24 \cdot 0$ & $<0.001$ \\
\hline
\end{tabular}

$P$ values determined by $\chi^{2}$ statistics.

tAnswered yes to the question 'In the last 12 months, were there any times when you ran out of food and could not afford to buy more?'.

$\ddagger$ Answered yes to the question 'Does your health limit the lifting or carrying of groceries?'.

§Answered no to the question 'Do you always have access to a car to do your food shopping?'.

likely to report limited car access for food shopping. Being born overseas was associated with an increased likelihood of reduced car access by over $50 \%$. Singleadult households without children were more than twice as likely to report limited car access, irrespective of the sex of the household member. Those with vocational education $(\mathrm{OR}=1 \cdot 60 ; 95 \% \mathrm{CI} 1 \cdot 04,2 \cdot 45)$ and no postschool qualifications ( $\mathrm{OR}=2 \cdot 28 ; 95 \% \mathrm{CI} 1 \cdot 62,3 \cdot 20)$ were more likely to not have car access to do food shopping compared with those having a bachelor degree. Compared with those in professional fields of employment, white-collar employees $(\mathrm{OR}=1 \cdot 64 ; 95 \%$ CI 1.04, 2.60) and those not in the labour force (OR $=3 \cdot 30 ; 95 \% \mathrm{CI}$ $2 \cdot 21,4.94)$ were significantly more likely to not have access to a car; however, no significant association was found for blue-collar employees. Households with annual incomes less than \$AU 36399 were less likely to have car access than households with incomes greater than \$AU 78000 , as were households in either the mid or most disadvantaged neighbourhoods compared with households in the least disadvantaged neighbourhoods.

\section{Discussion}

The present study adds to the food insecurity literature by describing the demographic and socio-economic distribution of food access restricted by a lack of money in Australia. Importantly, however, it extends our understanding about other limitations to food access, namely the extent and risk factors for physical limitations (i.e. inability to lift groceries) and a lack of access to reliable transport to do food shopping. We found that households where the main food shopper had low education, low 
Table 2 Multilevel logistic regression analysis of food insecurity (run out of money, difficulty carrying groceries, poor access to a car) and socio-demographic and socio-economic variables: the Victorian Lifestyle and Neighbourhood Environments Study, Melbourne, Australia, 2003

\begin{tabular}{|c|c|c|c|c|c|c|c|c|c|}
\hline & \multicolumn{3}{|c|}{ No money for foodt } & \multicolumn{3}{|c|}{ Difficulty lifting } & \multicolumn{3}{|c|}{ Do not have car access§ } \\
\hline & OR & $95 \% \mathrm{Cl}$ & & OR & $95 \% \mathrm{Cl}$ & & OR & $95 \% \mathrm{Cl}$ & \\
\hline \multicolumn{10}{|l|}{ Age (years)\| } \\
\hline $18-24$ & $1 \cdot 59$ & $0 \cdot 72,3 \cdot 51$ & & $0 \cdot 15$ & $0.04,0.65$ & *** & $2 \cdot 66$ & $1 \cdot 36,5 \cdot 21$ & ** \\
\hline $25-34$ & 0.95 & $0.61,1.48$ & & 0.35 & $0.22,0.54$ & $\star \star \star *$ & 1.09 & $0.73,1.63$ & \\
\hline $35-44$ & 0.91 & $0.61,1.35$ & & 0.57 & $0.40,0.79$ & $\star \star \star *$ & 0.98 & $0.68,1.43$ & \\
\hline $45-54$ & 1.00 & Ref. & & $1 \cdot 00$ & Ref. & & 1.00 & Ref. & \\
\hline $55-64$ & 0.52 & $0.32,0 \cdot 83$ & ** & $1 \cdot 54$ & $1 \cdot 15,2 \cdot 05$ & $\star *$ & $1 \cdot 45$ & $1 \cdot 00,2 \cdot 11$ & * \\
\hline$\geq 65$ & $0 \cdot 43$ & $0 \cdot 25,0 \cdot 74$ & $\star \star$ & $2 \cdot 57$ & $1.91,3.46$ & $\star \star \star *$ & $2 \cdot 48$ & $1 \cdot 73,3.55$ & $* * \star$ \\
\hline$P$ for trend & $\leq 0.001$ & & & $\leq 0.001$ & & & $\leq 0.001$ & & \\
\hline \multicolumn{10}{|l|}{ Country of birthll } \\
\hline Australia & $1 \cdot 00$ & Ref. & & $1 \cdot 00$ & Ref. & & $1 \cdot 00$ & Ref. & \\
\hline Overseas & $0 \cdot 75$ & $0.53,1.04$ & & $1 \cdot 60$ & $1 \cdot 29,1.99$ & $\star \star \star *$ & 1.53 & $1 \cdot 19,1 \cdot 96$ & 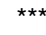 \\
\hline \multicolumn{10}{|l|}{ Household composition } \\
\hline Single adult male, no children & $3 \cdot 57$ & $2 \cdot 10,6 \cdot 08$ & $\star \star * \star$ & 0.68 & $0 \cdot 42,1 \cdot 10$ & & $2 \cdot 52$ & $1.58,4.03$ & *** \\
\hline Single adult female, no children & $3 \cdot 10$ & $1 \cdot 87,5 \cdot 16$ & 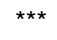 & $1 \cdot 11$ & $0 \cdot 76,1 \cdot 60$ & & $2 \cdot 57$ & $1 \cdot 73,3 \cdot 83$ & *** \\
\hline Single, with children & $4 \cdot 23$ & $2 \cdot 67,6 \cdot 72$ & $\star \star \star *$ & $1 \cdot 25$ & $0.84,1 \cdot 86$ & & $1 \cdot 40$ & $0.88,2 \cdot 23$ & \\
\hline Two or more adults, no children & $1 \cdot 07$ & $0.69,1.67$ & & $0 \cdot 84$ & $0 \cdot 63,1 \cdot 11$ & & 0.93 & $0.66,1.32$ & \\
\hline Two or more adults, with children & 1.00 & Ref. & & $1 \cdot 00$ & Ref. & & 1.00 & Ref. & \\
\hline \multicolumn{10}{|l|}{ Educationtt } \\
\hline Bachelor degree or higher & $1 \cdot 00$ & Ref. & & $1 \cdot 00$ & Ref. & & $1 \cdot 00$ & Ref. & \\
\hline Diploma & $2 \cdot 03$ & $1 \cdot 15,3 \cdot 59$ & * & $1 \cdot 07$ & $0 \cdot 70,1 \cdot 65$ & & $1 \cdot 29$ & $0 \cdot 80,2 \cdot 10$ & \\
\hline Vocational & $2 \cdot 74$ & $1 \cdot 67,4 \cdot 50$ & 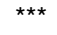 & $1 \cdot 45$ & $1 \cdot 01,2 \cdot 07$ & * & $1 \cdot 60$ & $1 \cdot 04,2 \cdot 45$ & * \\
\hline No post-school qualifications & $2 \cdot 56$ & $1 \cdot 66,3.97$ & $\star * *$ & 1.57 & $1 \cdot 18,2 \cdot 08$ & ** & $2 \cdot 28$ & $1 \cdot 62,3 \cdot 20$ & $\star * \star *$ \\
\hline$P$ for trend & $\leq 0.001$ & & & $\leq 0.001$ & & & $\leq 0.001$ & & \\
\hline \multicolumn{10}{|l|}{ Occupation $\ddagger$} \\
\hline Professional & $1 \cdot 00$ & Ref. & & $1 \cdot 00$ & Ref. & & 1.00 & Ref. & \\
\hline White-collar employees & $1 \cdot 56$ & $0 \cdot 93,2 \cdot 61$ & & $0 \cdot 86$ & $0.57,1.29$ & & $1 \cdot 64$ & $1 \cdot 04,2 \cdot 60$ & * \\
\hline Blue-collar employees & $1 \cdot 41$ & $0.68,2.94$ & & 0.68 & $0.36,1.28$ & & $1 \cdot 68$ & $0.90,3.14$ & \\
\hline Not in labour force & 3.00 & $1 \cdot 87,4 \cdot 81$ & $* * *$ & $2 \cdot 28$ & $1 \cdot 65,3 \cdot 17$ & 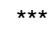 & $3 \cdot 30$ & $2 \cdot 21,4 \cdot 94$ & *** \\
\hline$P$ for trend & $\leq 0.001$ & & & $\leq 0.001$ & & & $\leq 0.001$ & & \\
\hline \multicolumn{10}{|l|}{ Incomeł‡ } \\
\hline$\$ A U 78000$ or more & 1.00 & Ref. & & 1.00 & Ref. & & 1.00 & Ref. & \\
\hline \$AU 52000-77999 & 1.69 & $0.73,3.92$ & & $1 \cdot 14$ & $0.75,1.75$ & & $1 \cdot 26$ & $0 \cdot 72,2 \cdot 18$ & \\
\hline \$AU $36400-51999$ & $4 \cdot 27$ & $1 \cdot 73,10 \cdot 55$ & $\star \star \star$ & $1 \cdot 43$ & $0.92,2.22$ & & 1.59 & $0.91,2 \cdot 80$ & \\
\hline \$AU 20800-36399 & $5 \cdot 90$ & $2 \cdot 27,15 \cdot 29$ & $\star \star \star \star$ & $2 \cdot 20$ & $1 \cdot 29,3 \cdot 78$ & $\star \star *$ & $2 \cdot 47$ & $1 \cdot 43,4 \cdot 26$ & 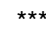 \\
\hline \$AU 20799 or less & $12 \cdot 68$ & $5 \cdot 15,31 \cdot 21$ & $\star \star \star \star ~$ & $5 \cdot 60$ & $3 \cdot 49,9 \cdot 00$ & 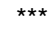 & $4 \cdot 60$ & $2 \cdot 57,8 \cdot 23$ & 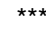 \\
\hline$P$ for trend & $\leq 0.001$ & & & $\leq 0.001$ & & & $\leq 0.001$ & & \\
\hline \multicolumn{10}{|l|}{ Area-level disadvantage $\S$} \\
\hline Least disadvantaged & $1 \cdot 00$ & Ref. & & $1 \cdot 00$ & Ref. & & $1 \cdot 00$ & Ref. & \\
\hline Mid disadvantaged & $1 \cdot 47$ & $0.91,2 \cdot 38$ & & $1 \cdot 50$ & $1 \cdot 10,2 \cdot 04$ & ** & $2 \cdot 44$ & $1 \cdot 38,4 \cdot 31$ & ** \\
\hline Most disadvantaged & $1 \cdot 47$ & $0 \cdot 89,2 \cdot 41$ & & 1.65 & $1 \cdot 20,2 \cdot 28$ & ** & $2 \cdot 35$ & $1 \cdot 32,4 \cdot 14$ & ** \\
\hline$P$ for trend & $0 \cdot 180$ & & & 0.003 & & & 0.006 & & \\
\hline
\end{tabular}

Ref., referent category.

$P$ value for trend determined by linear regression.

Significance of OR and $95 \% \mathrm{Cl}:{ }^{\star} P<0.05,{ }^{\star \star} P<0 \cdot 01,{ }^{\star \star \star} P<0.001$

tAnswered yes to the question 'In the last 12 months, were there any times when you ran out of food and could not afford to buy more?'.

$\ddagger$ Answered yes to the question 'Does your health limit the lifting or carrying of groceries?'.

§Answered no to the question 'Do you always have access to a car to do your food shopping?'.

IIUnadjusted.

- Adjusted for age.

t+Adjusted for age and country of birth.

$\ddagger \ddagger$ Adjusted for age, country of birth, household composition and education.

$\S \S$ Adjusted for age, country of birth, household composition, education, occupation and income.

income or was not in the labour force experienced restricted food access due to a lack of money, had difficulty lifting groceries and lacked access to a car to do food shopping. This means these groups are particularly vulnerable to poor nutritional outcomes due to lack of access to healthy food. Other important demographic predictors included age, household composition and country of birth: older age groups being at greater risk of having difficulty carrying groceries or not having access to a car; households where the food shopper was not born in Australia being more likely to be unable to lift groceries or not have access to a car; and households with only one adult having reduced access to a car and more likely to run out of money. Further, living in a disadvantaged area was also associated with an increased risk of being unable to carry groceries or not having access to a car to buy food independent of other confounders.

The trends observed in our study, of poor food access due to a lack of money and also functional limitation to lifting groceries or poor car access among low-income 
and other vulnerable populations such as the elderly and migrants, are consistent with previous studies ${ }^{(20,33)}$. However, differences in accessing food due to lack of money, difficulties lifting or lack of a car based on arealevel disadvantage have not been previously demonstrated. Previous studies of the relationship between the food environment and food access have concentrated on examining the availability and cost of healthy and unhealthy foods in relation to area-level socio-economic disadvantage $^{(34)}$. Further research is required to explore the relationship between neighbourhood or place and the economic and physical constraints experienced by households when trying to access food.

The present study confirms that income is an important determinant of food access. We found that those who were unemployed or on a very low income were three and twelve times more likely respectively to run out of food and have no money to buy more. Previous studies in Australia indicate for many families on government allowance or low incomes that the cost of a healthy diet can amount to over $40 \%$ of their income (average food expenditure in Australia is $12 \%$ of disposable income $)^{(35)}$. The cost of many healthy staple foods has risen recently in Australia $^{(36)}$ and it is likely that the cost of food will continue to rise ${ }^{(37)}$. In this situation it is essential that economic and social policies are put in place to support economic access for low-income families to a healthy diet.

Our results also identify a need to develop practical methods to assess food insecurity in these vulnerable populations who are at high nutritional risk, such as the elderly. It has been suggested that the assessment of food insecurity in the elderly should include not only indications that the person 'couldn't afford right foods for health' but also 'couldn't get the food I needed' and possibly 'was unable to prepare ${ }^{\text {(10) }}$. Intervening to ensure that vulnerable people have an assured access to food in their own homes is likely to be less costly than medical interventions for nutrition-related diseases.

While our study does document the distribution of food access restricted by a lack of money, it does not directly describe food access limited by physical limitations to food shopping. Rather it documents the distribution of physical limitations that may be associated with restricted food access. Further research is required to confirm the extent to which these factors actually restrict access to nutritious food in concert with and independent of economic factors. Interestingly, a study in Adelaide, Australia, has found that the food access problems for those without cars, particularly the elderly, can be mitigated by strong social or welfare networks ${ }^{\text {(38) }}$.

We could not assess the population prevalence of restricted food access because of the study design, whereby participants were sampled from least, mid and most disadvantaged small areas. However this sampling strategy had the benefit of maximising the socioeconomic gradient, thereby increasing our capacity to detect important socio-economic differences in food access. Additionally, the study is cross-sectional so we only comment on associations.

In Melbourne, access to food is compromised by a lack of money but household members also experience physical limitations to lifting groceries and lack of transport for food shopping. Economic and social policies need to address these issues to ensure the whole community has good economic access to nutritious food. Further research is required to confirm the impact of poor access on the nutritional quality of food purchased.

\section{Acknowledgements}

Sources of funding: C.B. is supported with a Public Health Research Fellowship from VicHealth. R.B. is supported by a National Health and Medical Research Council Capacity Building Grant (ID 324724). L.T. is supported by a National Health and Medical Research Council Capacity Building Grant (ID 425845). VicHealth provided the funding for the VicLANES study (2001-0436). Conflict of interest declaration: None. Authorship responsibilities: C.B. was responsible for study design, text drafting and editing; R.B. for data analyses and interpretation, text drafting and editing; L.T. for data analyses and interpretation, text drafting and editing; A.K. for study design, text drafting and editing. Acknowledgements: The authors thank Professor David Crawford, Associate Professor Gavin Turrell and Associate Professor Damien Jolley, who were Chief Investigators on the VicLANES project, and Tania King and Emma Rawlings, who led the fieldwork for the study. They also wish to acknowledge comments made by an anonymous reviewer and Ed Frongillo.

\section{References}

1. Australian Institute of Health and Welfare (2004) Physical Activity, Diet and Body Weight: Results from the 2001 National Health Survey. Risk Factors Data Briefing no. 1. Canberra: AIHW.

2. Begg S, Vos T, Barker B et al. (2007) The Burden of Disease and Injury in Australia, 2003. Canberra: AIHW.

3. Anderson SA (1990) Core indicators of nutritional state for difficult-to-sample populations. J Nutr 120, 1557-1600.

4. Wunderlich G \& Norwood J (editors) (2006) Food Insecurity and Hunger in the US: An Assessment of the Measure. Washington, DC: The National Academies Press.

5. Tarasuk VS \& Beaton GH (1999) Women's dietary intakes in the context of household food insecurity. J Nutr 129, 672-679.

6. Stuff JE, Casey PH, Szeto KL et al. (2004) Household food insecurity is associated with adult health status. J Nutr $\mathbf{1 3 4}$, 2330-2335.

7. Dinour LM, Bergen D \& Yeh MC (2007) The food insecurity-obesity paradox: a review of the literature and the role food stamps may play. J Am Diet Assoc 107, 1952-1961.

8. Seligman H, Bindman A, Vittinghoff E et al. (2007) Food insecurity is associated with diabetes mellitus: results from the National Health Examination and Nutrition Examination Survey (NHANES) 1999-2002. J Gen Intern Med 22, 1018-1023. 
9. World Health Organization (2003) Diet, Nutrition and the Prevention of Chronic Diseases. Report of a Joint WHO/FAO Expert Consultation. WHO Technical Report Series no. 916. Geneva: WHO.

10. Wolfe WS, Frongillo EA \& Valois P (2003) Understanding the experience of food insecurity by elders suggests ways to improve its measurement. J Nutr 133, 2762-2769.

11. Nord M, Andrews MS \& Carlson SJ (2008) Household Food Security in the United States, 2007. Washington, DC: US Department of Agriculture, Economic Research Service.

12. Che J \& Chen J (2001) Food insecurity in Canadian households. Health Rep 12, 11-22.

13. Dowler E (2001) Inequalities in diet and physical activity in Europe. Public Health Nutr 4, 701-709.

14. Parnell WR, Reid J, Wilson NC et al. (2001) Food security: is New Zealand a land of plenty? N Z Med J 114, 141-145.

15. Australian Bureau of Statistics (1998) National Nutrition Survey: Nutrient Intakes and Physical Measurements, Australia, 1995. Canberra: ABS.

16. Gallegos D, Ellies P \& Wright J (2008) Still there's no food! Food insecurity in a refugee population in Perth, Western Australia. Nutr Diet 65, 78-83.

17. Booth S (2006) Eating rough: food sources and acquisition practices of homeless young people in Adelaide, South Australia. Public Health Nutr 9, 212-218.

18. Booth ML, Wake M, Armstrong T et al. (2001) The epidemiology of overweight and obesity among Australian children and adolescents, 1995-97. Aust N Z J Public Health 25, 162-169.

19. Quine S \& Morrell S (2006) Food insecurity in communitydwelling older Australians. Public Health Nutr 9, 219-224.

20. White M (2007) Food access and obesity. Obes Rev 8, Suppl. 1, 99-107.

21. Wolfe W, Olson C, Kendall A et al. (1996) Understanding food insecurity in the elderly: a conceptual framework. J Nutr Educ 28, 92-100.

22. Wolfe WS, Olson CM, Kendall A et al. (1998) Hunger and food insecurity in the elderly: its nature and measurement. J Aging Health 10, 327-350.

23. Lee J, Frongillo E Jr \& Olson C (2005) Conceptualizing and assessing nutrition needs: perspectives of local program providers. J Nutr Elder 25, 61-82.

24. Lee JS \& Frongillo EA Jr (2001) Nutritional and health consequences are associated with food insecurity among US elderly persons. J Nutr 131, 1503-1509.
25. Lee JS \& Frongillo EA Jr (2001) Factors associated with food insecurity among US elderly persons: importance of functional impairments. J Gerontol B Psychol Sci Soc Sci 56, S94-S99.

26. Australian Bureau of Statistics (2006) Health of Older People in Australia: A Snapshot, 2004-05. Catalogue no. 4833.0.55.001. Canberra: ABS; available at http:// www.abs.gov.au/ausstats/abs@.nsf/mf/4833.0.55.001/

27. Australian Bureau of Statistics (2008) Survey of Motor Vehicle Use, Australia, 12 months ended 31 Oct 2007. Canberra: ABS.

28. Australian Bureau of Statistics (2008) Australian Social Trends, 2008. Catalogue no. 4102.0. Canberra: ABS; available at http://www.abs.gov.au/AUSSTATS/abs@.nsf/ Lookup/4102.OChapter3002008

29. Australian Bureau of Statistics (2001) Australian Standard Geographical Classification (ASGC). Canberra: ABS.

30. Australian Bureau of Statistics (1997) Australian Standard Classification of Occupations: Dictionary, 2nd ed. Catalogue no. 1220.0. Canberra: Australian Government Publishing Service.

31. Turrell G, Hewitt B, Patterson C et al. (2003) Measuring socio-economic position in dietary research: is choice of socio-economic indicator important? Public Health Nutr 6 , $191-200$

32. Klebanoff MA \& Cole SR (2008) Use of multiple imputation in the epidemiologic literature. Am J Epidemiol 168, 355-357.

33. Duerr L (2006) Prevalence of food insecurity and comprehensiveness of its measurement for older adult congregate meals program participants. J Nutr Elder 25, 121-146.

34. Cummins S \& Macintyre S (2006) Food environments and obesity - neighbourhood or nation? Int J Epidemiol 35, 100-104.

35. Kettings C, Sinclair AJ \& Voevodin M (2009) A healthy diet consistent with Australian health recommendations is too expensive for welfare-dependent families. Aust N ZJ Public Health 33, 566-572.

36. Harrison M, Lee A, Findlay M et al. (2010) The increasing cost of healthy food. Aust N Z J Public Health 34, 179-186.

37. Lock K, Stuckler D, Charlesworth K et al. (2009) Potential causes and health effects of rising global food prices. BMJ 339, b2403.

38. Coveney J \& O'Dwyer LA (2009) Effects of mobility and location on food access. Health Place 15, 45-55. 